\title{
Selecting a Location for a City Logistics Facility: A Fuzzy Synthetic Evaluation Method
}

\author{
Yan Zhang, ${ }^{*}$ Oh Kyoung Kwon**, Hwa-Joong Kim***
}

\begin{abstract}
The strategic location of city logistics facilities may help to establish more efficient urban logistics systems, reduce social and environmental costs of urban freight transport, and improve urban traffic conditions. In addition, it may allow a number of shippers or freight carriers to jointly operate freight vehicles and terminals or information systems while allowing them to have the capability to provide higher levels of services to their customers. This paper considers the problem of selecting a location for a city logistics facility while considering linguistic factors. This paper identifies the important factors in the selection of a location for a city logistics facility by performing a case study which applies the analytic hierarchy process method on data from Chongqing, China. The optimal location in Chongqing is then determined by using the fuzzy synthetic evaluation method. The results of this paper are expected to help municipal governments select appropriate locations for city logistics facilities and quantify the advantages and disadvantages of alternative locations.
\end{abstract}

Keywords: city logistics, facility location, fuzzy synthetic evaluation

Submission Date: 5/25/2011 Revision Date: 06/07/2011 Acceptance Date: 06/07/2011

* School of Economics and Management, Chongqing University of Post and Telecommunications Chongwen Road 2, Nanan District, Chongqing, 400065, CHINA

** Corresponding author, Professor, Graduate School of Logistics, Inha University, 253 Yonghyun-dong, Nam-gu, Incheon, 402-751, KOREA. Tel: +82 32860 7765, Fax: +82 32860 8226, E-mail: scm@inha.ac.kr

*** Professor, Graduate School of Logistics, Inha University, 253 Yonghyun-dong, Nam-gu, Incheon, 402-751, KOREA. 


\section{Introduction}

There are many problems concerning the movement of goods in urban areas, such as traffic congestion, negative environmental impacts, and high energy consumption. Although the delivery of goods is vitally important for residents and industries, there is a growing concern about how the essential flow of goods can be facilitated and the adverse impact of goods transport in urban areas can be reduced. Developing adequate city logistics facilities may be helpful in coping with these problems. City logistics facilities are complex logistics facilities located in areas surrounding a city; such facilities have multiple functions such as transshipment yards, warehouses, wholesale markets, information centers, exhibition halls, and meeting rooms, among others. Because of their strategic role, a considerable amount of research on city logistics facilities is needed to examine the decision-making process in terms of their roles and functions, sizes, locations, public- private partnerships, and so forth.

Among the various decision issues around city logistic facilities, this paper considers the problem of selecting a location for a logistics facility, which is a special case regarding the conventional facility location problem. In general, the conventional facility location problem has been analyzed by mathematical programming approaches such as the integer program, the dynamic program, the nonlinear program, the multi-objective program, the non-convex program, the quadradic program, and so forth. See Drezner and Hamacher (2001) for more information on the models and algorithms used to address conventional facility location problems. Mathematical programming approaches have generally focused on minimizing costs, which may be defined in terms of time, money, the number of trips, total distance, or additional measures. There are some qualitative factors as well, such as the proximity of suppliers and retailers, government policies, environmental factors, the quality of life, the availability of required technical labor, community attitudes, cultural attributes, the quality of schools, the availability of utilities, and so forth. However, humans are generally unsuccessful in making quantitative predictions and tend to be biased when they are forced to provide numerical estimates (Kahraman et al., 2003). Owing to the fuzzy models developed by Zadeh (1965), linguistic expressions for qualitative factors can be transformed into quantitative ones. Therefore, this paper uses the fuzzy synthetic evaluation (FSE) method, which considers a variety of factors in order to select a location for a city logistics facility.

To our knowledge, there has been no previous research using FSE to determine facility location decisions except for Kahraman et al. (2003), who summarized the procedures for the FSE and other fuzzy multi-criteria decision-making methods with numeric examples. 
However, they did not apply the methods to a real case. In this regard, this paper provides a review of the previous research which used other fuzzy set theories to address facility location decisions. Tzeng and Chen (1999) considered the problem of determining the optimal number and sites of fire stations in international airports. The objective was to minimize the weighted sum of the setup and loss costs. The setup cost is the cost required to open a new fire station, and the loss cost is that caused by an insufficient reaction to an aircraft accident because of an insufficient number of fire stations. The problem was represented by a fuzzy multi-objective model and solved by using a genetic algorithm. Kuo et al. (1999) developed a decision support system by using the fuzzy analytic hierarchy process (AHP) to determine the location of new convenience stores. Chen (2001) considered the problem of selecting a distribution center under the fuzzy environment and suggested a multiple criteria decision-making method. In the model, the ratings of each location alternative and the weights of each criterion are described by linguistic variables which can be expressed by triangular fuzzy numbers. Kuo et al. (2002) extended their previous work (Kuo et al.,1999) by incorporating a neural network method to study the relation ship between the examined variables and store performance. Chou et al. (2008) presented a fuzzy multi-criteria decision-making model for selecting a location for an international tourist hotel in Taiwan. The fuzzy set theory, linguistic value, hierarchical structur eanalysis, and fuzzy analytic hierarchy process methods were used to consolidate decision makers' assessments about criteria weightings. Bashiri and Hosseininezhad (2009) considered a multi-facility location problem of minimizing the total distance traveled between facilities. The fuzzy AHP was used to obtain the weights between facilities, and a two-phase fuzzy linear programming model was suggested to solve the problem. Vahidnia et al. (2009) addressed the problem of developing an efficient distribution network of hospitals in an urban area in Tehran, Iran by using a fuzzy AHP. They developed a network for delivering its services to the target population with a minimal amount of time, pollution, and expenditure. Onut et al. (2010) considered the problem of selecting a shopping center site for a real-world application in Istanbul, Turkey. They proposed a multi-criteria decision-making method combining the fuzzy AHP and fuzzy TOPSIS (technique for order preference by similarity to ideal solution) methods, where the fuzzy AHP is used for assigning the weights of the criteria and the fuzzy TOPSIS is used to determine the best alternative by using those criteria weights.

The rest of the current paper proceeds as follows: the following section describes the detailed procedure of the fuzzy synthetic evaluation method, followed by a case study using data from Chongqing, China. The results and implications are then presented in Section 3, and the paper concludes with a summary of the research results and suggestions for future research in Section 4. 


\section{Research Method}

The fuzzy synthetic evaluation method used in this research uses fuzzy mathematics to transform and eliminate unclear data and has multiple factors which are used for evaluating candidates (Kuo and Chen, 2006). The method obtains final evaluation scores of candidates by considering the evaluations of experts and the weights of their factors. In general, the FSE method follows the following procedure: (1) construct a hierarchy framework of affecting factors; (2) determine the weights of each factor by using the AHP; (3) generate fuzzy judgment matrices; (4) generate decision-making sets; and (5) defuzzify the final fuzzy sets and rank the candidates. Steps 3, 4, and 5 are further elaborated because Steps 1 and 2 are the same as those in the AHP. See Saaty (1980) for more information on the AHP. For simplicity sake, let the factor in the upper level of a hierarchy of factors used in the AHP be the category and the decomposed factors from the categories simply be the factors. In the application of the fuzzy set theory, this paper uses triangular fuzzy numbers as the membership functions.

\section{Step 3. Generation of Fuzzy Judgment Matrices}

The fuzzy judgment matrix is a matrix obtained after evaluators' grades on factors are fuzzified. Suppose that there are $N$ number of evaluators and $M$ number of grades, that $g_{j k l}^{i}$ denotes the number of evaluators who give grade $i$ on factor $j$ of category $k$ for candidate $l$, and that $\left(a_{i}, b_{i}, c_{i}\right)$ denotes the fuzzy number vectors in the fuzzy member function corresponding to grade $i$. The member function $f_{i}(x)$ for grade $i$ will be defined as

$$
f_{i}(x)=\left\{\begin{array}{l}
\frac{x-a_{i}}{b_{i}-a_{i}} \text { if } a_{i} \leq x \leq b_{i} \\
\frac{c_{i}-x}{c_{i}-b_{i}} \text { if } b_{i} \leq x \leq c_{i} \\
0 \quad \text { otherwise }
\end{array}\right.
$$

Then, fuzzy number vectors $y_{j k l}$ corresponding to factor $j$ of category $k$ for candidate $l$ is then calculated by using

$$
\boldsymbol{y}_{j k l}=\frac{\sum_{i=1}^{M} g_{j k l}^{i}\left(a_{i}, b_{i}, c_{i}\right)}{N}
$$


In addition, the row vector $m, r_{j k l}^{m}$, of the fuzzy judgment matrix for factor $j$ of category $k$ for candidate $l$ is obtained by mapping the fuzzy number $y_{j k l}$ on the fuzzy scale. To facilitate the understanding of the mapping method, consider an example for factor $j$ of category $k$ for candidate $l$ with the data as follows: $N=40, M=5$ (in linguistic grading terms, there are "excellent," "good," "moderate," "bad," and "the worst"), corresponding fuzzy number vectors in the fuzzy member function are given as $(0.8,1.0,1.0),(0.6,0.8,1.0)$, $(0.3,0.5,0.7),(0.0,0.2,0.4)$, and $(0.0,0,0.2)$ for the linguistic grades "excellent," "good," "moderate," "bad," and "the worst," respectively, and the number of evaluators $g_{j k l}^{i}$ are 14, $15,6,4$, and 1 for each grade $i$. Then the fuzzy number $y_{j k l}$ is calculated as follows

$$
\begin{aligned}
y_{j k l}= & \frac{1}{40} \times[14 \times(0.8,1,1)+15 \times(0.6,0.8,1)+6 \times(0.3,0.5,0.7) \\
& \quad+4 \times(0,0.2,0.4)+(0,0,2)] \\
= & (0.55,0.745,0.875)
\end{aligned}
$$

The row vector $m, r_{j k k}^{m}$, becomes $(0.23,0.83,0.38,0,0)$, calculated by mapping the fuzzy numbers $(0.55,0.745,0.875)$ on the fuzzy scale (Figure 1$)$.

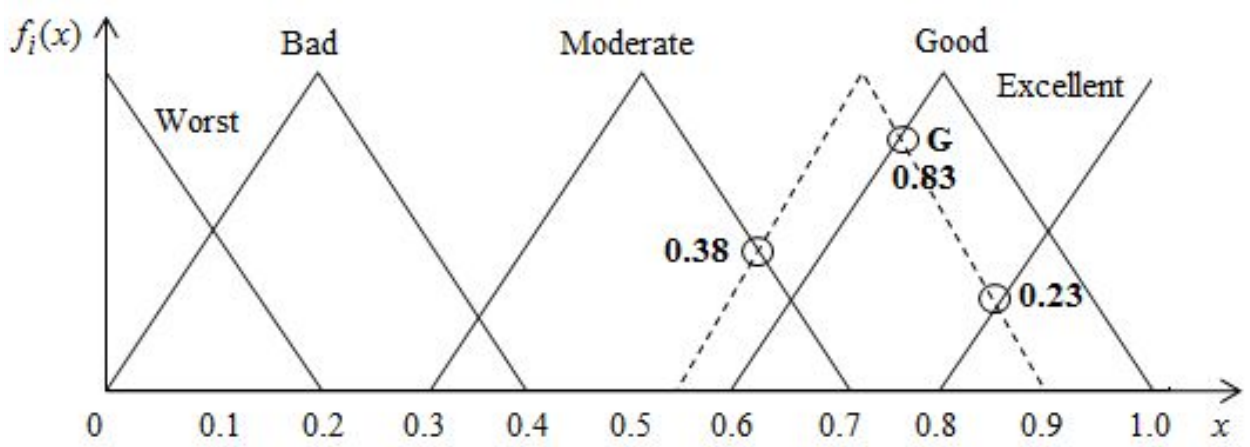

Figure 1.

Mapping on the fuzzy scale

Finally, the fuzzy judgment matrix $\boldsymbol{R}_{j k l}$ corresponding to factor $j$ of category $k$ for candidate $l$ is 


$$
R_{j k l}=\left[\begin{array}{c}
r_{j k l}^{1} \\
r_{j k l}^{2} \\
\vdots \\
r_{j k l}^{J}
\end{array}\right]
$$

where $J$ is the total number of factors in category $k$.

\section{Step 4. Generation of the Decision Making Sets}

In this step, we generate the decision-making vectors for each category and candidate. The vector is obtained by multiplying the fuzzy judgment matrix for each category and candidate. The weight vector of each category is determined through the AHP analysis in Step 2. Suppose that $W_{k}$ denotes the weight vector of category $k$. Then the decisionmaking vector $D_{k l}$ for category $k$ and candidate $l$ is calculated as $D_{k l}=W_{k} \times R_{k l}$. Finally, the decision-making vector for candidate $l, D_{l}$, is generated by

$$
D_{l}=W \times\left[\begin{array}{c}
D_{1 l} \\
D_{2 l} \\
\vdots \\
D_{K l}
\end{array}\right]
$$

where $W$ denotes the weight vector consisting of categories' weights obtained by the AHP.

Step 5. Defuzzification of the Final Fuzzy Sets and the process to determine the Ranking of the Candidates

Defuzzification involves the calculation of the crisp value of the fuzzy number. The crisp value can approximate the deterministic characteristics of the fuzzy reasoning process and help transform uncertain values into applicable ones when solving real-world problems. Defuzzification is done by using

$$
K_{k l}=D_{k l} \times S \text { and } K_{l}=D_{l} \times S
$$

where $K_{k l}$ and $D_{k l}$ are the defuzzification scores and the decision-making vector for category $k$ and candidate $l, K_{l}$ and $D_{l}$ are the defuzzification scores and the decisionmaking vector for candidate $l$, whereas $S$ is the point set of grades. Once we get the defuzzification score, the ranking of the candidates is obtained by comparing the 
defuzzification scores.

\section{Case Study}

For this case study, we selected Chongqing, China, the fourth largest city in China after Beijing, Shanghai, and Tianjin. The Chinese government has invested heavily in the city's infrastructure to make the city the key gateway to Western China. In addition, it is still the only city in Western China with sufficient infrastructure (e.g., water supply, roads, and an airport) capable of supporting successful logistics. Although Chongqing has geographic and economic advantages and is supported by the Chinese government, the city still has problems which prevent it from being the hub city of Western China. Some of the current problems include: high logistics costs, traffic congestion, insufficient logistics facilities, a lack of transparency in the shipping process, and the loss, damage or pilferage of goods, among others. Furthermore, Chongqing city authorities currently want to construct logistics facilities in the city. Therefore, we performed this case study to determine a site for a logistics facility before the Chinese Government.

\section{Determination of Candidates, Factors, and the Hierarchy of the Factors}

As described earlier, the AHP is used in the FSE method to determine the weights of categories and factors. To do so, we determined an initial set of candidate locations and factors used in the AHP and the FSE methods. This research began with three possible candidate locations for the city logistics facility. Note that although candidate locations should be selected from a large number of locations, we did not begin with a large number because the city authorities had already performed the selection process and were only interested in selecting the optimal location among these three candidates. The candidate locations were the Chongqing New North Zone (CNNZ), Shapingba Qu (SBQ), and Jiulongpo Qu (JPQ), which are star-marked in Figure 2. 


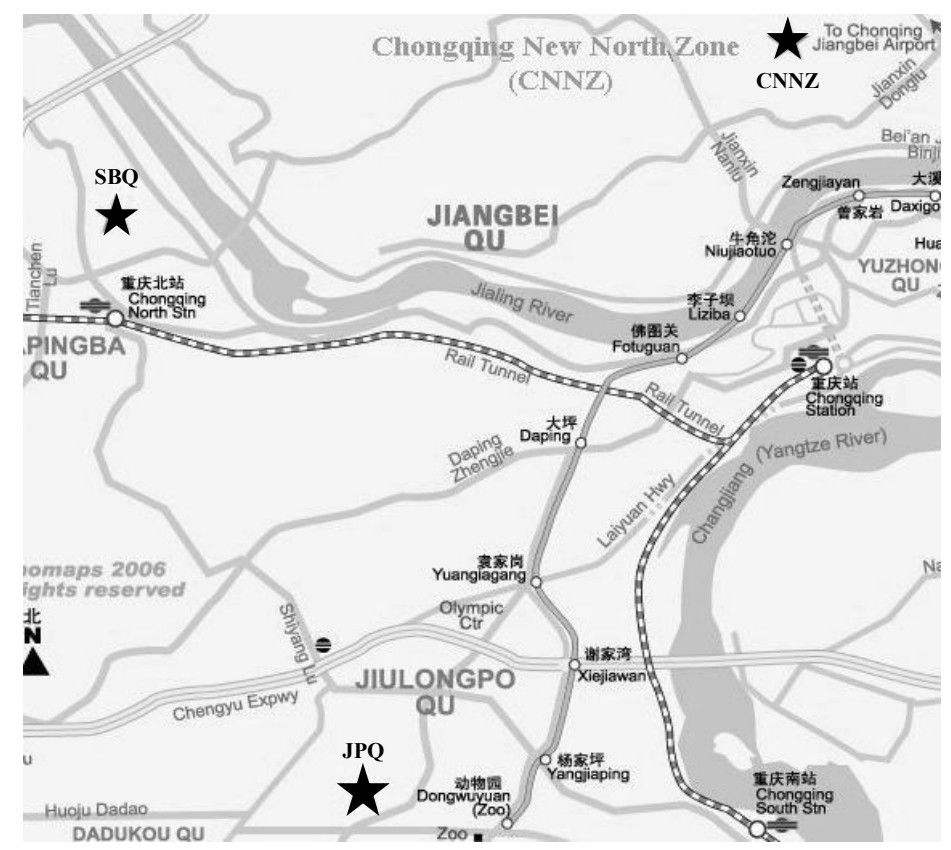

Figure 2.

Three candidate locations in Chongqing,China

To establish the evaluation factors, we first selected 30 factors which affect a location decision (See Table 1), between Chuang (2001), Yang and Lee (1997), Partovi (2006), and Chen (2001). We then interviewed 40 staff members who were selected randomly from the Chongqing Municipal Development and Reform Commission, a department responsible for researching and coordinating solutions for issues related to logistics, researching and proposing strategies for logistics, implementing policies and measures to promote the logistics industry, planning and constructing regional logistics centers, and providing leadership in formulating logistics infrastructure projects.

To identify the relevant factors, the respondents were asked to rate each factor with respect to the selection of a city logistics facility by using a 3-point scale ("very important," "important," and "less important"). Table 1 summarizes the results of the survey. The mean value of each factor was determined by averaging the multiplication of the number of respondents with the values of 3,2 and 1 corresponding to "very important," "important," and "less important," respectively. As shown in Table 1, 32 was the natural cutoff point because it was the average of the highest, i.e., 38.667, and the lowest, i.e., 25.333. Using the cutoff value, we then selected 13 factors whose mean values were no less than the cutoff value; four factors belonged to the transportation proximity category, four factors to surrounding areas, three factors to land features, and two factors to macro-environment. 
However, for the matrix calculation used in the FSE method, the number of relevant criteria belonging to each category needed to be the same. Therefore, we selected additional factors -- "regional use," belonging to land features, and "social impacts" and "access restrictions," belonging to the macro environment -- although their mean values were less than the cutoff value. The hierarchy of categories and factors is summarized in Figure 3, and the definitions of all factors are shown in Table 2.

\section{Table 1.}

Factors affecting the selection of a city logistics facility

\begin{tabular}{|c|c|c|c|c|}
\hline Factor & $\begin{array}{c}\text { Very } \\
\text { important }\end{array}$ & Important & $\begin{array}{c}\text { Less } \\
\text { important }\end{array}$ & Mean \\
\hline 1. Commerce size & 36 & 4 & 0 & 38.667 \\
\hline 2. Economy size & 36 & 3 & 1 & 38.333 \\
\hline 3. Port & 34 & 6 & 0 & 38.000 \\
\hline 4. Highway & 29 & 11 & 0 & 36.333 \\
\hline 5. Railway & 29 & 11 & 0 & 36.333 \\
\hline 6. Land price & 27 & 12 & 1 & 35.333 \\
\hline 7. Airport & 25 & 15 & 0 & 35.000 \\
\hline 8. Corporation size & 26 & 12 & 2 & 34.667 \\
\hline 9. Number of developed zones & 23 & 16 & 1 & 34.000 \\
\hline 10. Expansion possibility & 24 & 13 & 3 & 33.667 \\
\hline 11. Availability of utilities & 21 & 18 & 1 & 33.333 \\
\hline 12. Basic cost & 20 & 18 & 2 & 32.667 \\
\hline 13. Environmental restriction & 18 & 20 & 2 & 32.000 \\
\hline 14. Market growth potential & 16 & 22 & 2 & 31.333 \\
\hline 15. Region use & 15 & 23 & 2 & 31.000 \\
\hline 16. Proximity to market & 14 & 25 & 1 & 31.000 \\
\hline 17. Business climate & 16 & 20 & 4 & 30.667 \\
\hline 18. Social impact & 12 & 26 & 2 & 30.000 \\
\hline 19. Access restriction & 11 & 25 & 4 & 29.000 \\
\hline 20. Quality of police, fire, medical services & 10 & 27 & 3 & 29.000 \\
\hline 21. Availability of labor & 10 & 25 & 5 & 28.333 \\
\hline 22. Proximity to raw material & 8 & 29 & 3 & 28.333 \\
\hline 23. Prevailing wage rates & 9 & 26 & 5 & 28.000 \\
\hline 24. Availability of skilled workers & 6 & 30 & 4 & 27.333 \\
\hline 25. Ambience/cost of living & 7 & 28 & 5 & 27.333 \\
\hline 26. Tax incentive concessions & 4 & 32 & 4 & 26.667 \\
\hline 27. Cost of utilities & 5 & 29 & 6 & 26.333 \\
\hline 28. Community environment & 4 & 31 & 5 & 26.333 \\
\hline 29. Unemployment ratio of surrounding areas & 4 & 29 & 7 & 25.667 \\
\hline 30. Industrial pollution control & 2 & 32 & 6 & 25.333 \\
\hline
\end{tabular}




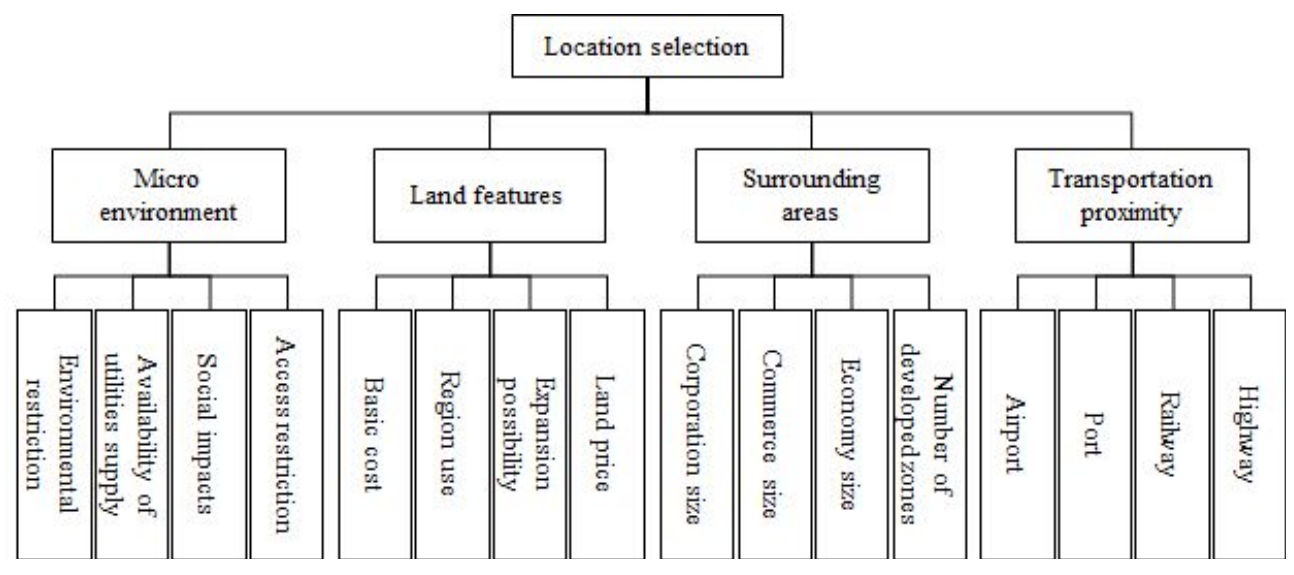

Figure 3.

Hierarchy of categories and factors

Table 2.

Definition of factors

\begin{tabular}{|c|c|c|}
\hline Category & Factor & Definition \\
\hline \multirow{4}{*}{$\begin{array}{c}\text { Transportation } \\
\text { Proximity }\end{array}$} & Highway & Number of highways surrounding the candidate location \\
\hline & Railway & $\begin{array}{l}\text { Distance from the candidate location to the nearest } \\
\text { railway station }\end{array}$ \\
\hline & Port & Distance from the candidate location to the nearest port \\
\hline & Airport & $\begin{array}{l}\text { Distance from the candidate location to the nearest } \\
\text { airport }\end{array}$ \\
\hline \multirow{4}{*}{$\begin{array}{c}\text { Land } \\
\text { Features }\end{array}$} & Land price & Land price declared by the authority \\
\hline & $\begin{array}{l}\text { Expansion } \\
\text { Possibility }\end{array}$ & $\begin{array}{l}\text { Ratio of undeveloped commercial land to all available } \\
\text { land }\end{array}$ \\
\hline & Region use & $\begin{array}{l}\text { Comparison based on the city plan and the land use } \\
\text { code }\end{array}$ \\
\hline & Basic cost & Cost of land leveling and groundwork \\
\hline \multirow{3}{*}{$\begin{array}{l}\text { Surrounding } \\
\quad \text { Areas }\end{array}$} & $\begin{array}{c}\text { Number of } \\
\text { developed zones }\end{array}$ & $\begin{array}{l}\text { Number of counties/development zones within } 50 \text { square } \\
\text { kilometers surrounding the candidate location }\end{array}$ \\
\hline & Economy size & $\begin{array}{l}\text { Gross Regional Product and industrial output of } \\
\text { counties/developing zones within } 50 \text { square kilometers } \\
\text { surrounding the candidate location (their amount and } \\
\text { growth rates) }\end{array}$ \\
\hline & Commerce size & $\begin{array}{l}\text { Retail sales of counties/developing zones within } 50 \\
\text { square kilometers surrounding the candidate location (their } \\
\text { amount and growth rates) }\end{array}$ \\
\hline
\end{tabular}




\begin{tabular}{|c|c|c|}
\hline Category & Factor & Definition \\
\hline & Corporation size & $\begin{array}{l}\text { Number of corporations with more than } 10 \text { million RMB } \\
\text { in assets }\end{array}$ \\
\hline \multirow{4}{*}{$\begin{array}{l}\text { Macro } \\
\text { Environment }\end{array}$} & $\begin{array}{l}\text { Access } \\
\text { restriction }\end{array}$ & $\begin{array}{l}\text { Restrictions on movements of freight vehicles from the } \\
\text { candidate location to surrounding areas according to the } \\
\text { time, size, or weight of the vehicles (based on the local } \\
\text { traffic code) }\end{array}$ \\
\hline & $\begin{array}{l}\text { Availability of } \\
\text { utilities }\end{array}$ & $\begin{array}{l}\text { Availability and planned availability of electrical power, } \\
\text { water, natural gas, and telecommunications infrastructure }\end{array}$ \\
\hline & Social impact & $\begin{array}{l}\text { Number of people who must move and noise and air } \\
\text { pollution from facility construction }\end{array}$ \\
\hline & $\begin{array}{l}\text { Environmental } \\
\text { restriction }\end{array}$ & $\begin{array}{l}\text { Local codes for air pollution, noise pollution, and } \\
\text { emissions }\end{array}$ \\
\hline
\end{tabular}

\section{Weight Determination of Categories and Factors by the AHP}

As described earlier, this research used the AHP to obtain the weight set of the factors. For this purpose, we designed and distributed another questionnaire which consisted of the categories and factors shown in Figure 3. These categories were compared in a pair-wise fashion, and produced values from 1 to 9 scale ratings. The questionnaire was issued to 100 staff members in 10 logistics-related government departments. A total of 76 questionnaires were returned. Discarding 8 invalid questionnaires yielded a total of 68 valid questionnaires (a valid response rate of 68\%). For the AHP analysis, we used Expert Choice, a commercial AHP software package. During this research, the questionnaire was eliminated if the CR (consistency ratio) for any questionnaire was more than 0.1 . Otherwise, the degree of consistency was satisfactory.

Table 3 summarizes the weights of the categories and factors, which were used in the FSE method. As shown in Table 3, all categories were acceptable because all CRs were less than 0.1. Furthermore, the weight of the category "surrounding areas" was the highest among the four categories, which suggests that the city logistics facility needs to be built in a place which has a large surrounding economy size, number of developed zones, commerce size and corporation size. Note that the weight set summarized in Table 3 was used in the FSE analysis. 
Table 3.

Weights of categories and factors

\begin{tabular}{|c|c|c|c|c|c|}
\hline Category & Weight & $\mathrm{CR}$ & Factor & Weight & $\mathrm{CR}$ \\
\hline \multirow{4}{*}{$\begin{array}{c}\text { Transportation } \\
\text { proximity }\end{array}$} & \multirow{4}{*}{0.382} & \multirow{16}{*}{0.097} & Highway & 0.423 & \multirow{4}{*}{0.003} \\
\hline & & & Railway & 0.227 & \\
\hline & & & Port & 0.227 & \\
\hline & & & Airport & 0.123 & \\
\hline \multirow{4}{*}{$\begin{array}{l}\text { Surrounding } \\
\text { areas }\end{array}$} & \multirow{4}{*}{0.471} & & $\begin{array}{c}\text { Number of developed } \\
\text { zones }\end{array}$ & 0.073 & \multirow{4}{*}{0.024} \\
\hline & & & Economy size & 0.352 & \\
\hline & & & Commercial size & 0.494 & \\
\hline & & & Corporation size & 0.081 & \\
\hline \multirow{4}{*}{ Land features } & \multirow{4}{*}{0.109} & & Land price & 0.633 & \multirow{4}{*}{0.072} \\
\hline & & & Expansion possibility & 0.196 & \\
\hline & & & Region use & 0.056 & \\
\hline & & & Basic cost & 0.115 & \\
\hline \multirow{4}{*}{$\begin{array}{c}\text { Macro } \\
\text { environment }\end{array}$} & \multirow{4}{*}{0.038} & & Access restriction & 0.153 & \multirow{4}{*}{0.002} \\
\hline & & & Social impact & 0.153 & \\
\hline & & & Availability of utilities & 0.511 & \\
\hline & & & $\begin{array}{l}\text { Environmental } \\
\text { restriction }\end{array}$ & 0.183 & \\
\hline
\end{tabular}

To highlight the important factors in the selection of the location for the city's logistics facility, we performed the AHP analysis again by using only the selected factors. These results are summarized in Table 4. The factors "commerce size", "economy size", " number of highways", "ports", and "railways" were the most important considerations in the city logistics location decision. This implies that a good location for a city logistics facility is a site which has a large surrounding area with a high volume of gross regional products, industry output, and retail sales. The facility also needs to be close to highways, railways, and inland ports. 
Table 4.

Priority ranking and weights of factors

\begin{tabular}{c|c|c}
\hline $\begin{array}{c}\text { Priority } \\
\text { ranking }\end{array}$ & Factor & Weight \\
\hline 1 & Commerce size & 0.233 \\
\hline 2 & Economy size & 0.169 \\
\hline 3 & Highway & 0.162 \\
\hline 4 & Port & 0.087 \\
\hline 5 & Railway & 0.087 \\
\hline 6 & Land price & 0.069 \\
\hline 7 & Airport & 0.047 \\
\hline 8 & Corporation size & 0.038 \\
\hline 9 & Number of developed zones & 0.034 \\
\hline 10 & Expansion possibility & 0.021 \\
\hline 11 & Availability of utilities & 0.019 \\
\hline 12 & Basic cost & 0.013 \\
\hline 13 & Environmental restriction & 0.007 \\
\hline 14 & Region use & 0.006 \\
\hline 15 & Social impact & 0.006 \\
\hline 16 & Access restriction & 0.006 \\
\hline & &
\end{tabular}

\section{Location Selection using the FSE Method}

In order to effectively evaluate the CNNZ, SBQ, and JPQ locations, another questionnaire consisting of candidate locations, categories, and factors was designed (values from 1 to 5 scale ratings). This questionnaire was issued to 40 experts (employees of the Chongqing Municipal Development and Reform Commission and professors at Chongqing Jiao Tong University). The evaluators were familiar with the concept, the function of logistics centers, and the state and circumstances of the candidates and hence had sufficient experience to make an educated comparison of the candidates. In the FSE analysis, we set the deffuzification scores of "excellent", "good", "moderate", "bad", and "worst" as 100, 80, 60, 40, and 20, respectively, and set the fuzzy number vectors in the member functions for the fuzzy numbers as $(0.8,1.0,1.0),(0.6,0.8,1.0),(0.3,0.5,0.7)$, $(0.0,0.2,0.4)$, and $(0.0,0,0.2)$ for the linguistic terms "excellent", "good", "moderate", "bad" and "worst", respectively. The results of the questionnaire are summarized in Table 5. For example, with respect to the factor "highway" for the CNNZ, 14 experts marked "excellent", 15 experts, "good", 6 experts, "moderate", 4 experts, "bad," and 1 expert, "worst". 
Table 5.

Experts' judgment regarding the candidate locations

\begin{tabular}{|c|c|c|c|c|c|c|c|c|c|c|c|c|c|c|c|c|}
\hline \multirow{2}{*}{ Category } & \multirow{2}{*}{ Factors } & \multicolumn{5}{|c|}{ CNNZ } & \multicolumn{5}{|c|}{ SBQ } & \multicolumn{5}{|c|}{ JPQ } \\
\hline & & $E^{\dagger}$ & $\mathrm{G}^{\dagger}$ & $\mathrm{M}^{\dagger}$ & $\mathrm{B}^{\dagger}$ & $\mathrm{W}^{\dagger}$ & $\mathrm{E}$ & $\mathrm{G}$ & M & $\mathrm{B}$ & W & E & $\mathrm{G}$ & M & $\mathrm{B}$ & W \\
\hline \multirow{4}{*}{$\begin{array}{c}\text { Transportation } \\
\text { proximity }\end{array}$} & Highway & 14 & 15 & $6^{*}$ & 4 & 1 & 6 & 13 & 15 & 3 & 3 & 5 & 9 & 21 & 3 & 2 \\
\hline & Railway & 8 & 12 & 14 & 4 & 2 & 1 & 13 & 17 & 6 & 3 & 6 & 12 & 15 & 1 & 6 \\
\hline & Port & 8 & 12 & 13 & 6 & 1 & 1 & 1 & 15 & 14 & 9 & 7 & 9 & 15 & 6 & 3 \\
\hline & Airport & 15 & 12 & 10 & 2 & 1 & 3 & 6 & 16 & 5 & 10 & 6 & 3 & 15 & 8 & 8 \\
\hline \multirow{4}{*}{$\begin{array}{c}\text { Surrounding } \\
\text { areas }\end{array}$} & $\begin{array}{l}\text { Number of } \\
\text { developed } \\
\text { zones }\end{array}$ & 12 & 13 & 12 & 1 & 2 & 10 & 12 & 11 & 4 & 3 & 8 & 10 & 19 & 2 & 1 \\
\hline & $\begin{array}{l}\text { Economy } \\
\text { size }\end{array}$ & 4 & 15 & 10 & 6 & 5 & 12 & 11 & 12 & 2 & 3 & 15 & 10 & 12 & 2 & 1 \\
\hline & Commerce size & 10 & 8 & 12 & 7 & 3 & 12 & 8 & 13 & 5 & 2 & 14 & 9 & 11 & 3 & 3 \\
\hline & $\begin{array}{l}\text { Corporation } \\
\text { size }\end{array}$ & 12 & 11 & 11 & 3 & 3 & 11 & 9 & 12 & 7 & 1 & 7 & 17 & 13 & 2 & 1 \\
\hline \multirow{4}{*}{$\begin{array}{l}\text { Land } \\
\text { features }\end{array}$} & Land price & 10 & 14 & 12 & 3 & 1 & 6 & 11 & 15 & 3 & 5 & 7 & 10 & 12 & 6 & 5 \\
\hline & $\begin{array}{l}\text { Expansion } \\
\text { possibility }\end{array}$ & 21 & 7 & 6 & 4 & 2 & 6 & 7 & 10 & 10 & 7 & 8 & 18 & 9 & 2 & 3 \\
\hline & Region use & 13 & 13 & 7 & 4 & 3 & 3 & 10 & 17 & 5 & 5 & 1 & 9 & 18 & 11 & 1 \\
\hline & Basic cost & 6 & 20 & 9 & 4 & 1 & 1 & 12 & 18 & 7 & 2 & 1 & 13 & 17 & 6 & 3 \\
\hline \multirow{4}{*}{$\begin{array}{c}\text { Macro } \\
\text { environment }\end{array}$} & $\begin{array}{c}\text { Access } \\
\text { restriction }\end{array}$ & 14 & 12 & 9 & 2 & 3 & 6 & 2 & 10 & 17 & 5 & 3 & 8 & 24 & 4 & 1 \\
\hline & Social impact & 11 & 12 & 11 & 3 & 3 & 8 & 14 & 11 & 4 & 3 & 4 & 7 & 17 & 8 & 4 \\
\hline & $\begin{array}{l}\text { Availability } \\
\text { of utilities }\end{array}$ & 9 & 15 & 12 & 1 & 3 & 8 & 16 & 12 & 2 & 2 & 8 & 14 & 9 & 7 & 2 \\
\hline & $\begin{array}{c}\text { Environmental } \\
\text { impact }\end{array}$ & 9 & 7 & 18 & 4 & 2 & 3 & 6 & 20 & 8 & 3 & 3 & 9 & 19 & 7 & 2 \\
\hline
\end{tabular}

†E: Excellent, G: Good, M: Moderate, B: Bad, W: Worst.

* Number of experts.

Finally, after applying Procedure 1 by using the data in Tables 3 and 5, we obtained the final scores and rankings of the candidates (Table 6). The results in Table 6 clearly indicate that the CNNZ is the optimal location for a new city logistics facility in Chongqing. In addition, the CNNZ ranked the best in terms of transportation proximity, land features, and the macro environment. The difference between the score of the CNNZ and those of the other candidates was substantial. This also implies that the CNNZ is better positioned in terms of transportation infrastructure, land features, and macro environment. However, the surrounding area is the most important factor in the selection of a city logistics facility, and the area surrounding the CNNZ was voted as being less favorable than those surrounding SBQ and JPQ. Although the CNNZ exhibited lower economic and Commerce sizes than the other candidates, the CNNZ showed a higher potential than the others in terms of Gross Regional Product, industry output, and the total volume of retail 
sales. In addition, the CNNZ is a new zone which was established by the Chongqing municipal government in 2001 and has since enjoyed economic support in terms of taxes, finances, and investment incentives from the municipal government. The CNNZ is also expected to become a modernized industrial base with high-tech industries as its foundation and an urban landscape demonstration zone. Therefore, its economic and commerce size are expected to improve in the near future. In the long run, we feel that the CNNZ is likely to become the optimal location for a city logistics facility in Chongqing.

\section{Table 6.}

Scores and ranking of the candidate locations

\begin{tabular}{c|c|c|c|c}
\hline \multirow{2}{*}{$\begin{array}{c}\text { Transportation } \\
\text { proximity }\end{array}$} & Score & 98.658 & 74.126 & JPQ \\
\cline { 2 - 5 } & Rank & 1 & 3 & 2 \\
\hline \multirow{2}{*}{$\begin{array}{c}\text { Surrounding } \\
\text { areas }\end{array}$} & Score & 81.825 & 84.367 & 86.316 \\
\cline { 2 - 5 } & Rank & 3 & 2 & 1 \\
\hline \multirow{2}{*}{\begin{tabular}{c} 
Land features \\
\cline { 1 - 5 }
\end{tabular}} & Score & 97.729 & 79.784 & 85.267 \\
\cline { 2 - 5 } Macro & Rank & 1 & 3 & 2 \\
\hline \multirow{2}{*}{\begin{tabular}{c} 
Total \\
\cline { 2 - 5 }
\end{tabular}} & Score & 91.377 & 86.831 & 83.071 \\
\hline & Rank & 1 & 2 & 3 \\
\cline { 2 - 5 } & Score & 90.447 & 80.049 & 81.881 \\
\hline
\end{tabular}

\section{Conclusions}

This paper examined the problem of selecting a location for a city logistics facility in Chongqing while considering the linguistic multiple factors; the problem was solved by using the AHP and FSE methods. By using the AHP method, the important factors in the location decision were clearly identified, and the problem was structured systematically. Such a method enabled decision makers to examine the strengths and weaknesses of alternative locations by comparing them against appropriate factors. The results of the FSE method suggested that when making a location decision on a city logistics facility, the most important factor category was Commerce size. Of the three candidate locations considered, the Chongqing New North Zone was the best.

We'd like to point out that this research does have some limitations. Firstly, the fuzzy 
synthetic evaluation method does not provide a means to detect inconsistencies in the rating process. For example, in the AHP, the CR can be calculated to determine inconsistencies in the rating process. Secondly, the questionnaires were issued only to government employees and professors. As such, the perception of the alternative locations' performance might have been biased because the survey did not include private-sector experts. In this regard, future research is warranted to apply the proposed model to other cities and to include private-sector managers in the survey. In addition, the use of other fuzzy multi-attribute approaches such as the fuzzy TOPSIS and fuzzy outranking methods may be beneficial in the prioritization of alternative locations. 